\title{
COMPARISON OF CAR PERFORMANCE USING HVO FUEL AND DIESEL FUEL
}

\author{
Kristaps Sondors $^{1}$, Ilmars Dukulis ${ }^{1}$, Vilnis Pirs ${ }^{1}$, Aivars Birkavs ${ }^{1}$, Gints Birzietis ${ }^{1}$, Maris Gailis ${ }^{1,2}$ \\ ${ }^{1}$ Latvia University of Life Sciences and Technologies, Latvia; ${ }^{2}$ Riga Technical University, Latvia \\ kristaps.sondors@gmail.com, ilmars.dukulis@1lu.lv, vilnis.pirs@1lu.lv, aivars.birkavs@llu.lv, \\ gints.birzietis@llu.lv, maris.gailis@rtu.lv
}

\begin{abstract}
All member states of the European Union are bound to the EU directives and regulations on the reduction of greenhouse gas emissions and the use of renewable energy sources in road transport. As the objectives defined in these documents cannot be achieved only by the mandatory blending of biofuels, opportunities to use new generation biofuels in pure form have to be investigated. One of the most promising fuel types in this matter could be hydrotreated vegetable oil (HVO), which can be produced from a variety of non-food raw materials. To determine the effect of fuel on the car's dynamic, economic and environmental performance, experimental studies were carried out using a car model Opel Insignia powered by pure HVO fuel (NExBTL manufactured by Neste $\mathrm{Oil}$ ) and regular diesel fuel. The tests were performed on a power bench, but the AVL measuring equipment was used to determine the exhaust gas composition and fuel consumption. The experimental results show that the power and torque characteristics in the whole range of engine speed are similar when operated with NExBTL and fossil diesel. The average NExBTL fuel volumetric consumption is about $3 \%$ higher, fuel mass consumption $5.3 \%$ lower and fuel energy input $4.5 \%$ lower compared to diesel fuel. This can be explained by the differences between the physical properties of the tested fuels, such as density, lower heating value and compressibility. Exhaust components, which are usually compared in studies of different fuels, using NExBTL fuel tend to decrease compared to fossil diesel. A reduction was observed in most driving modes tested. Unburned hydrocarbons decreased on average by $44 \%, \mathrm{SO}_{2}-$ by $13.3 \%, \mathrm{NO}_{\mathrm{x}}$ by $5 \%$ and $\mathrm{CO}_{2}-$ by $3.8 \%$. Experimental studies show that NExBTL fuel might compete with fossil diesel in the future. It is confirmed by measurements of power, fuel consumption and exhaust gas content. An important drawback for the wider implementation of this fuel is its production cost.
\end{abstract}

Keywords: hydrotreated vegetable oil, renewable energy, power, torque, fuel consumption, exhaust emissions.

\section{Introduction}

Directive 2018/2001 of the European Parliament and the Council on the promotion of the use of energy from renewable sources determines that each Member State has to oblige fuel suppliers to ensure that the share of energy from renewable sources within the final energy consumption in the transport sector is at least $14 \%$ by 2030 . Moreover, the contribution of advanced biofuels and biogas produced from the feedstock listed in Annex of the Directive (for example, algae, bio-waste, straw, palm oil mill effluent etc.) as a share of the final consumption of energy in the transport sector has to be at least $0.2 \%$ in 2022, at least $1 \%$ in 2025 and at least $3.5 \%$ in 2030 [1].

Current experience shows that these goals cannot be achieved only by the mandatory blending of biofuels. Consequently, the use of advanced or next-generation biofuels has to be investigated in their pure form. One of the most promising fuel types in this concern could be hydrotreated vegetable oil (HVO), which can be produced from a variety of non-food raw materials.

Most of the largest fuel manufacturers have developed HVO refining processes and even named their products. NExBTL (short for "next-generation bioliquid") is the trade name for HVO manufactured by Neste Oil (Finland). Product of Universal Oil Products (UOP)-Eni (UK, Italy) has the trade name "Green Diesel", but the HVO produced by SK energy (Korea) is called HBD (hydro-gen-treating biodiesel) [2].

HVO is a relatively new fuel, so it has been more widely studied only in the last decade. There are a few hundred serious publications and reviews that investigate the production, combustion, performance, fuel consumption, and exhaust emissions of this fuel type. Fuels with different physical properties, in pure form or in blends, on engine test stands and in whole vehicles have been examined. For these reasons, the obtained results and trends of individual parameters are different [3].

Eleven passenger cars with different exhaust gas after-treatment systems and emission standards (from Euro 3 to Euro 6), different injection systems and transmissions were tested at the Technology Transfer Centre Automotive of the Coburg University of Applied Sciences and Arts. The results showed that the emissions of passenger cars using HVO decreased from $35 \%$ to $90 \%$ of the unburned 
components $(\mathrm{HC}, \mathrm{CO})$ emissions, compared to diesel fuel. $\mathrm{NO}_{\mathrm{x}}$ emissions increased between $5 \%$ and $14 \%$ versus diesel fuel, and the increase was independent of the exhaust treatment [4].

The effect of HVO fuel and blends with diesel fuel on the emissions and performance of a passenger car size diesel engine was investigated at the Czech Technical University in Prague. Using pure HVO increased the indicated power by $4.53 \%$. Significant drops compared to diesel fuel in CO and HC emissions were obtained (61.8\% and 64.3\%). Emissions of $\mathrm{CO}_{2}$ and $\mathrm{NO}_{\mathrm{x}}$ slightly decreased (accordingly by $3.56 \%$ and $4.2 \%$ ) [5].

Research on the combustion, energy and emission parameters of various concentration blends of NExBTL fuel and diesel fuel in a compression-ignition engine was performed in Lithuania and Hungary. The analysis of combustion rates did not show significant changes. The volumetric HVO fuel consumption was increased by $4 \%$ to $6 \%$ compared to diesel fuel. The variation in $\mathrm{CO}$ was insignificant. The decrease of $\mathrm{CO}_{2}$ was up to $0.35 \%$, and the maximum decrease was reached when the percentage of NExBTL increased up to $85-100 \%$. The $\mathrm{NO}_{\mathrm{x}}$ amount was reduced by up to $20 \%$ depending on the engine load. The HC concentration was reduced by $12 \%$ to $25 \%$ at different speed modes [6].

Two Euro $6 \mathrm{~b}$ compliant diesel passenger cars were tested in real driving conditions using five different fuel blends including pure HVO fuel at different air temperatures in the Vehicle Emission Laboratory at the European Commission-Joint Research Centre Ispra, Italy. The use of different HVO blends and diesel did not lead to fuel-related trends on the emissions of the tested vehicles, not in the laboratory and not on road. The use of pure $\mathrm{HVO}$ resulted in $4 \%$ lower $\mathrm{CO}_{2}$ emissions than the other fuel tested in all analysed conditions [7].

As more research has been done on engine test stands and using different fuel blends with HVO content from $5 \%$ to $80 \%$, the aim of this study is to investigate using pure $\mathrm{HVO}$ in a non-adapted typical passenger car.

\section{Materials and methods}

The tests running the car Opel Insignia 2.0 CDTi on the chassis dynamometer Mustang MD-1750 have been carried out at the Alternative Fuel Research Laboratory of the Latvia University of Life Sciences and Technologies (See Figure 1).

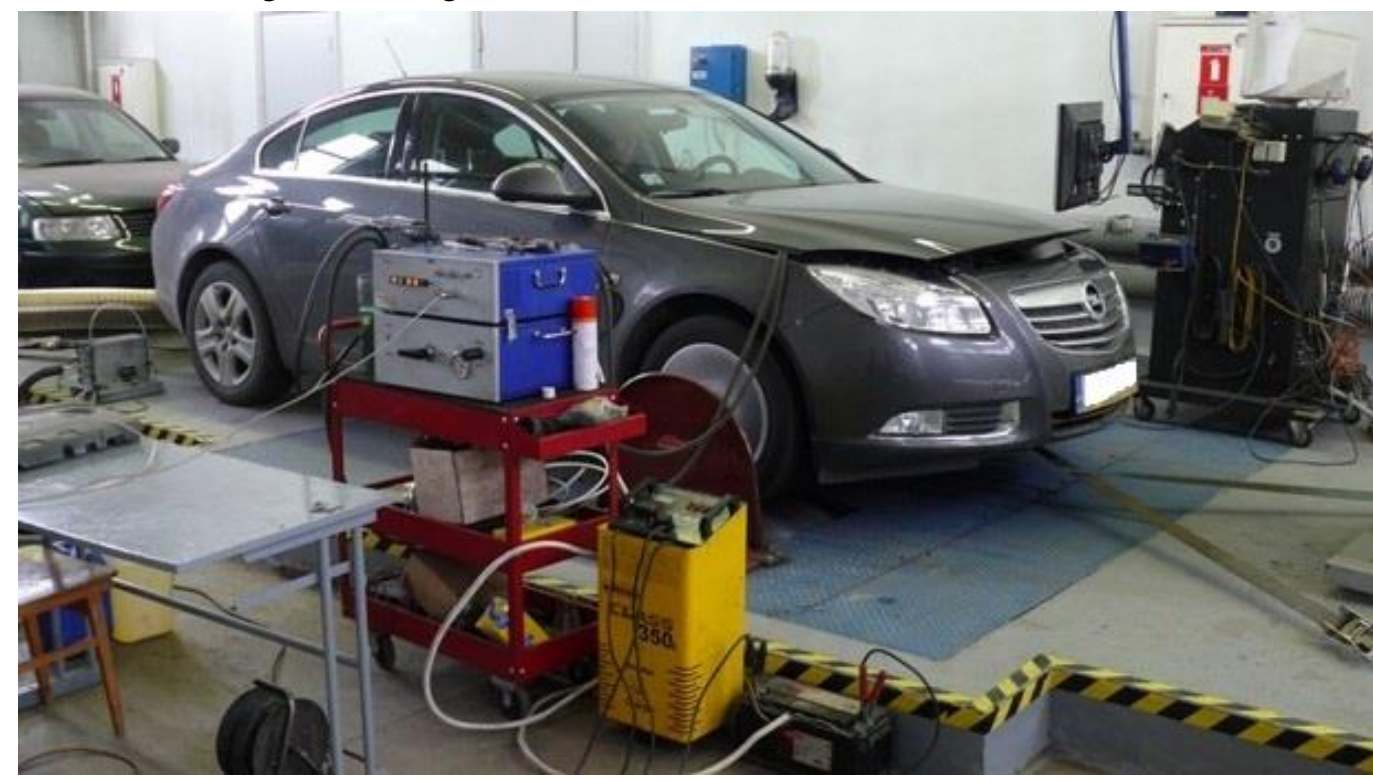

Fig. 1. Tested car on the chassis dynamometer

Two different fuels were used in the experiments:

- fossil arctic diesel fuel, class 0 (Diesel);

- hydrotreated vegetable oil fuel produced by Neste Oil (NExBTL).

The main fuel parameters were determined at the certified laboratory of the Porvoo Refinery, Finland (See Table 1). 
Main parameters of tested fuels

\begin{tabular}{|l|c|c|c|}
\hline \multicolumn{1}{|c|}{ Parameter } & Test method & Diesel & NExBTL \\
\hline Density $(\rho)$ at $15^{\circ} \mathrm{C}, \mathrm{kg} \cdot \mathrm{m}^{-3}$ & ENISO12185 & 836.3 & 778.9 \\
\hline Viscosity at $40^{\circ} \mathrm{C}^{-3} \mathrm{~mm}^{2} \cdot \mathrm{s}^{-1}$ & ENISO3104 & 2.581 & 2.884 \\
\hline Lowest heating value $\left(L H V_{\text {mass }}\right), \mathrm{MJ} \cdot \mathrm{kg}^{-1}$ & ASTMD4809 & 43.535 & 43.894 \\
\hline Lowest heating value $\left(L H V_{\text {volume }}\right), \mathrm{MJ} \cdot{ }^{-1}$ & - & $36.408^{*}$ & $34.189^{*}$ \\
\hline Cetane number by IQT-analyser & ASTMD6890 & 52.4 & 74.7 \\
\hline
\end{tabular}

${ }^{*}$ Lowest heating value in $\mathrm{MJ} \cdot \mathrm{l}^{-1}$ is calculated from the measured lowest heating value in $\mathrm{MJ} \cdot \mathrm{kg}^{-1}$ and density

The main parameters of the test vehicle Opel Insignia 2.0 CDTi:

- year of production - 2011;

- four-cylinder diesel engine with a displacement of $1956 \mathrm{~cm}^{3}$;

- maximum power $96 \mathrm{~kW}$ at $4000 \mathrm{~min}^{-1}$;

- maximum torque $300 \mathrm{~N} \cdot \mathrm{m}$ at $1750-2500 \mathrm{~min}^{-1}$;

- engine compression ratio 16.5 ;

- common rail fuel injection.

The following facilities and systems were used for measurement:

- the chassis dynamometer Mustang MD-1750 for power and torque measurements on the vehicle wheels;

- the AVL KMA Mobile fuel consumption measuring device, using the zero resistance geared flow meter;

- the exhaust gas analytical system AVL SESAM FTIR.

The layout of the experimental equipment is shown in Figure 2.

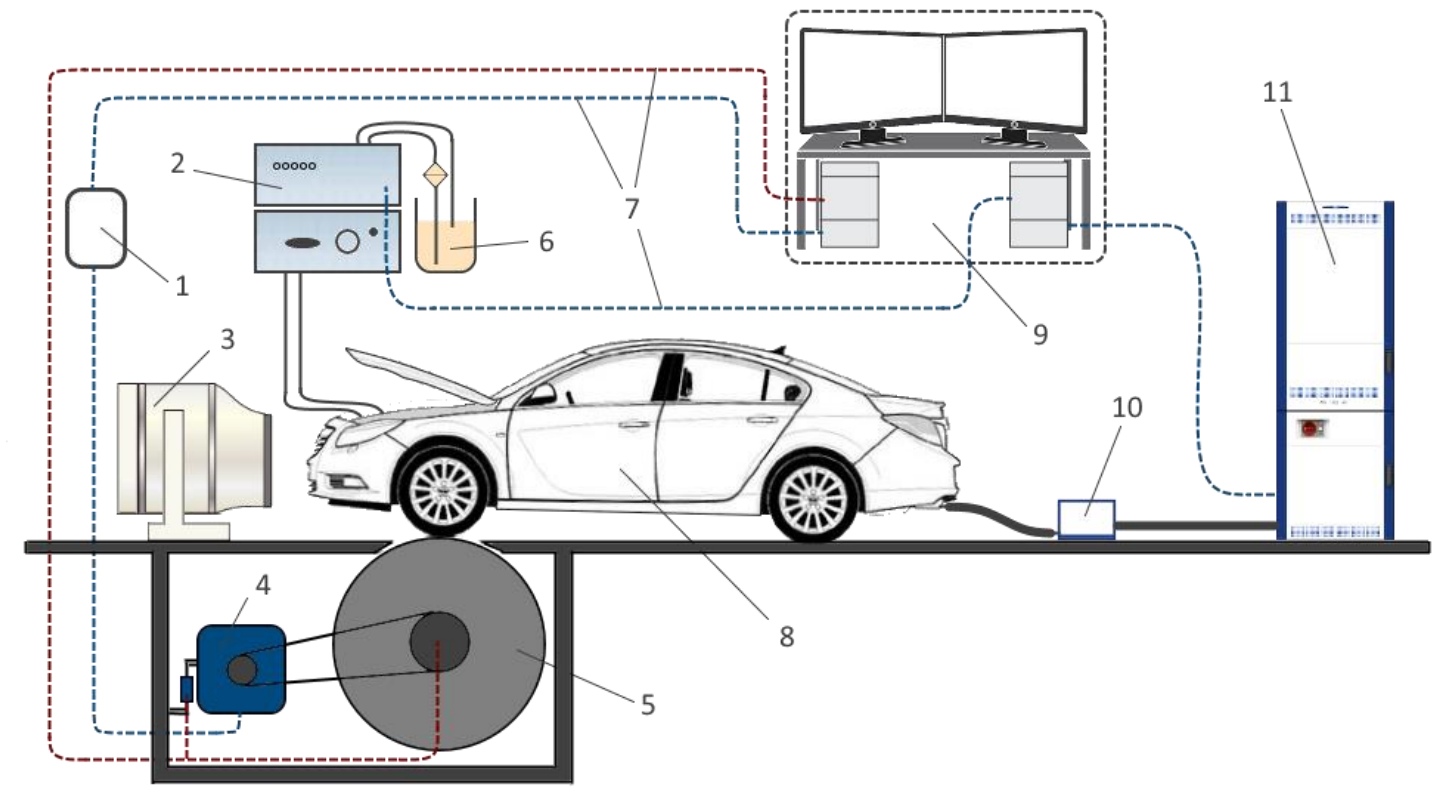

Fig. 2. Layout of the experimental equipment: 1 - dynamometer control box; 2 - fuel measuring device AVL KMA Mobile; 3 - air blower; 4 - power absorber unit; 5 - chassis dynamometer Mustang $M D$-1750; 6 - fuel tank; 7 - data communication cables; 8 - experimental car; 9 - PCs with special software; 10 - heated filter; 11 - multicomponent exhaust gas measurement system AVL SESAM FTIR

Exhaust gas analytical system software calculates $\mathrm{NO}_{\mathrm{x}}$ concentration in a gas sample by the following equation [8]:

$$
\mathrm{NO}_{x}=\mathrm{NO}+\mathrm{NO}_{2},
$$

where $N O-$ concentration of nitrogen oxide; 
$\mathrm{NO}_{2}$ - concentration of nitrogen dioxide.

Another calculated parameter of the exhaust gas analytical system is the concentration of hydrocarbons, by the following equation [8]:

$$
\mathrm{HC}=\mathrm{CH}_{4}+2 \cdot \mathrm{C}_{2} \mathrm{H}_{2}+2 \cdot \mathrm{C}_{2} \mathrm{H}_{4}+2 \cdot \mathrm{C}_{2} \mathrm{H}_{6}+3 \cdot \mathrm{C}_{3} \mathrm{H}_{8}+7.5 \cdot \mathrm{C}_{7} \mathrm{H}_{8}+10 \cdot \mathrm{C}_{8} \mathrm{H}_{18},
$$

where $\mathrm{CH}_{4}$ - concentration of methane;

$\mathrm{C}_{2} \mathrm{H}_{2}$ - concentration of ethine;

$\mathrm{C}_{2} \mathrm{H}_{4}$ - concentration of ethene;

$\mathrm{C}_{2} \mathrm{H}_{6}$ - concentration of ethane;

$\mathrm{C}_{3} \mathrm{H}_{8}$ - concentration of propane;

$\mathrm{C}_{7} \mathrm{H}_{8}$ - concentration of toluene;

$\mathrm{C}_{8} \mathrm{H}_{18}$ - concentration of n-octane.

The tests and the sequence of their execution have been approved in several previous studies, including experiments performed with the same car running on blends of $7 \%$ biodiesel and $7 \%$ hydrotreated vegetable oil with fossil diesel [9].

The following series of tests with each of the fuel samples were performed:

- maximal power and torque measurement tests;

- fuel consumption and exhaust emission analysis during idling and at constant driving speeds of $50 \mathrm{~km} \cdot \mathrm{h}^{-1}, 90 \mathrm{~km} \cdot \mathrm{h}^{-1}$ and $110 \mathrm{~km} \cdot \mathrm{h}^{-1}$;

- fuel consumption while performing two different driving cycles:

- $\quad$ IM-240 - combined 240-second test representing a $3.1 \mathrm{~km}$ route with an average speed of $47.3 \mathrm{~km} \cdot \mathrm{h}^{-1}$ and a maximum speed of $91.2 \mathrm{~km} \cdot \mathrm{h}^{-1}$;

- in-house developed Jelgava city cycle, based on real driving data - urban 360-second test representing a $2.36 \mathrm{~km}$ route with an average speed of $23.3 \mathrm{~km} \cdot \mathrm{h}^{-1}[10]$.

Each test series were performed with at least 3 repetitions. The air temperature in the laboratory was maintained between $+18{ }^{\circ} \mathrm{C}$ and $+22^{\circ} \mathrm{C}$.

The car's power and torque curves were obtained by operating it in fourth gear with the accelerator pedal fully pressed. These characteristics reflect the car's power and torque on the driven wheels.

The instant fuel consumption, test time and speed values were used to calculate the average fuel consumption at constant speed in litres per $100 \mathrm{~km}$ :

$$
Q_{100}=\frac{1}{n} \cdot \sum_{i=1}^{n}\left(\frac{100}{v \cdot t} \cdot \sum_{i=1}^{k} Q_{i n s t}\right),
$$

where $Q_{100}$ - average fuel consumption, 1 per $100 \mathrm{~km}$;

$n$ - number of repetitions;

$v$ - vehicle speed, $\mathrm{km} \cdot \mathrm{h}^{-1}$;

$t$ - continuation of one test repetition, s;

$k$ - number of instant determinations;

$Q_{\text {inst }}-$ instant fuel consumption, $1 \cdot \mathrm{h}^{-1}$.

The average fuel consumption performing driving cycles was calculated using the relationship:

$$
Q_{100}=\frac{1}{n} \cdot \sum_{i=1}^{n}\left(\frac{100 \cdot t}{3600 \cdot s} \cdot \sum_{i=1}^{k} Q_{i n s t}\right),
$$

where $s$-distance covered during the repetition, $\mathrm{km}$.

The average relative amount of each exhaust gas component in all test modes was calculated using the relationship:

$$
E G C=\frac{1}{n} \cdot \sum_{i=1}^{n}\left(\frac{1}{t} \cdot \sum_{i=1}^{k} E G C_{\text {inst }}\right),
$$

where $E G C$-average relative amount of the exhaust gas component, ppm (parts per million); 
$E G C_{\text {inst }}$ - instant relative amount of the exhaust gas component, ppm.

\section{Results and discussion}

Comparing the average values of power and torque with the values of each repetition, the correlation of the torque and power data points exceeded $99.5 \%$. Using the power and torque average values at particular crankshaft rotations, the power and torque curves were created (see Fig. 3).

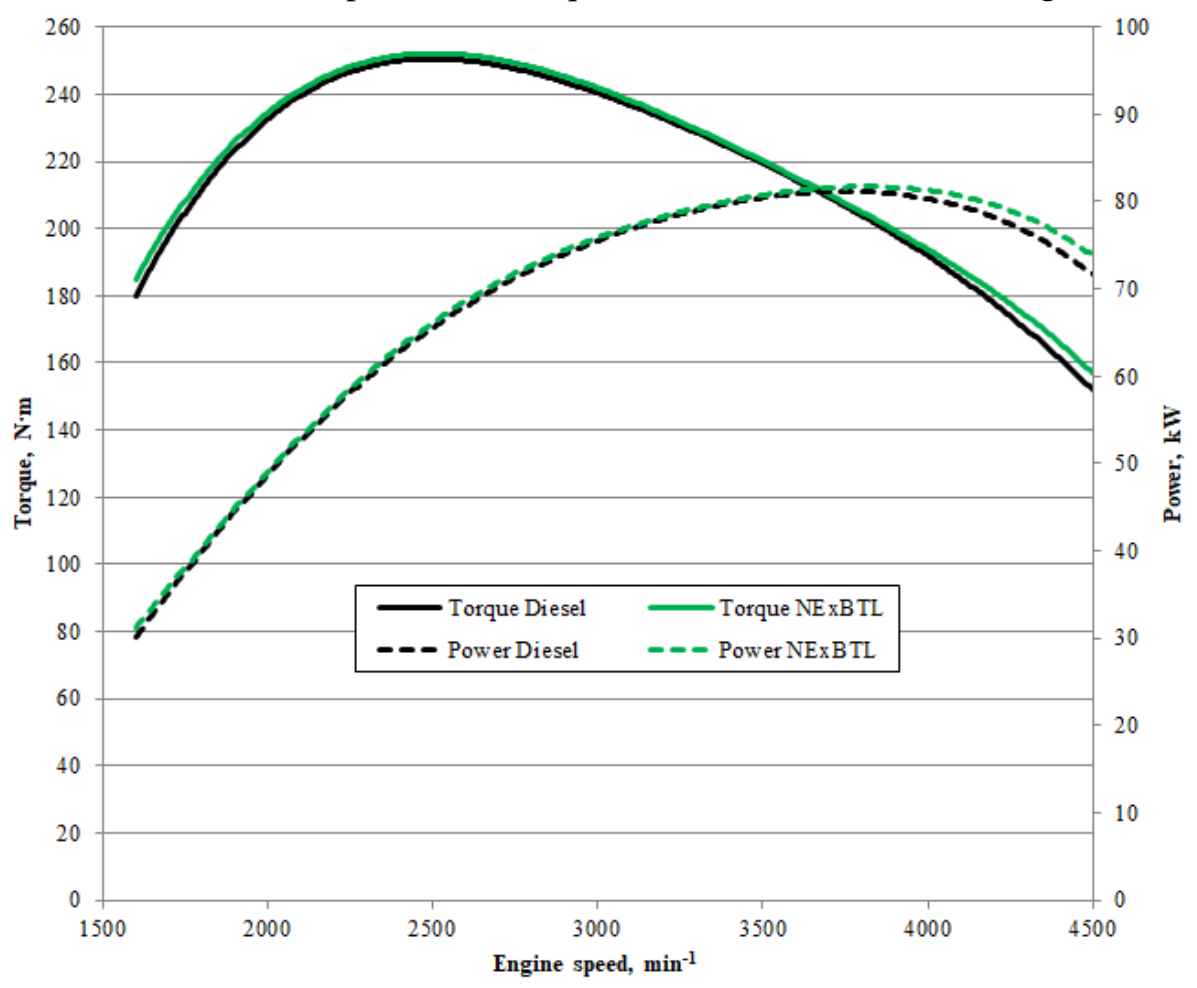

Fig. 3. Power and torque measurement results

The experimental results show that when working with both fuels, the car's power and torque characteristics in the entire range of the engine speed are similar. When running a car on NExBTL, the average increase in power and torque compared to fossil diesel is $1 \%$. The maximum power of the car with NExBTL $82.1 \mathrm{~kW}$ is reached at $3760 \mathrm{~min}^{-1}$, but with fossil diesel $-81.8 \mathrm{~kW}$ at $3700 \mathrm{~min}^{-1}$. The maximum power difference is $0.34 \%$. The maximum torque with NExBTL $252.8 \mathrm{~N} \cdot \mathrm{m}$ is reached at $2400 \mathrm{~min}^{-1}$, but with fossil diesel $-250.9 \mathrm{~N} \cdot \mathrm{m}$ at $2360 \mathrm{~min}^{-1}$. The maximum torque difference is $0.75 \%$. As a common rail fuel system distributes fuel on a volumetric basis, and NExBTL has lower LHV per volume, one may expect a decrease of engine maximal torque when the engine runs on NExBTL. The observed increase of the torque and power can be explained by the following. It can be assumed that during the maximal power and torque test, the engine control unit (ECU) will respond to the driver's torque request by increasing the inlet air pressure, the fuel pressure in the common rail and injector opening timing similarly for both tested fuels. At particularly high fuel pressure (close and above 1000 bar), which is normally set by ECU when maximal torque is provided in such engines, the effects of fluid compressively must be evaluated. Boehman et al. reported that the bulk modulus of compressibility of regular diesel fuel and paraffinic distillate (which can represent NExBTL) is respectively $1477 \mathrm{MPa}$ and $1318 \mathrm{MPa}$ at temperature $27.8^{\circ} \mathrm{C}$ and pressure $6.89 \mathrm{MPa}$ [11]. The equation for calculation of the bulk modulus of compressibility is [11]:

$$
B=\left(P-P_{0}\right) \cdot \frac{V_{0}}{V_{0}-V},
$$

where $B$-bulk modulus of compressibility, MPa;

$P$ - pressure after compression, $\mathrm{MPa}$;

$P_{0}$ - pressure before compression, MPa;

$V$ - initial volume of fluid, $\mathrm{mm}^{3}$; 


\section{$V_{0}$-volume of fluid after compression, $\mathrm{mm}^{3}$.}

The larger is the bulk modulus of compressibility, the smaller is the volume reduction during compression of the fluid. The bulk modulus is not constant and normally increases with the applied pressure, as the molecules of the fluid are compressed closer to each other. The authors calculated relative volume reduction of the two fuels of interest when compressed from 1 to $1000 \mathrm{bar}$, using equation (6) and the bulk modulus of compressibility from [11]:

- diesel fuel - volume reduction by $6.77 \%$;

- NExBTL - volume reduction by $7.59 \%$.

In the specific case of the fuel injection system, the actual volume of the fuel that is compressed is constant, and fuel mass increases according to the compressibility of the fluid.

By introducing the definitions of density and LHV, an equation for evaluation of fuel compressibility on energy amount is developed:

$$
E_{f c}=V_{0}+\frac{V_{0} \cdot\left(P-P_{0}\right)}{B} \cdot \rho \cdot L H S_{\text {mass }},
$$

where $\rho$-fuel density, $\mathrm{kg} \cdot \mathrm{mm}^{-3}$;

$E_{f c}$ - energy amount of injected volume of compressed fuel, MJ;

$L H V_{\text {mass }}$ - lower heating value, $\mathrm{MJ} \cdot \mathrm{kg}^{-1}$;

$V_{c}$ - compressed volume of fluid, $\mathrm{mm}^{3}$.

Evaluation results of energy supplied in a combustion chamber at 1000 bar fuel pressure show that for a similar compressed volume of fuel, fuel energy ratio $E_{N E x B T L} / E_{\text {Diesel }}$ is 0.946 or in other words, there is $5.37 \%$ less energy in an equal volume of compressed fuel at 1000 bars, comparing NExBTL to diesel fuel.

The energy amount in each fuel and differences in compressibility cannot fully explain observed similarities of torque and power. The explanation why the torque or power curves are so close in this experiment lies in further analysis of fuel and energy use in other driving tests.

In contrary to maximal torque and power test, during constant engine speed (idle) and constant driving (50, 90 and $110 \mathrm{~km} \cdot \mathrm{h}^{-1}$ ) speed tests, the fuel is supplied not at a constant volume but in just enough mass flow (or energy flow) to produce required torque. The same applies to the driving cycle (IM-240 and Jelgava) tests.

The average diesel fuel consumption in idling mode is $0.499 \pm 0.058$ litres per hour and for NExBTL is $0.504 \pm 0.020$ litres per hour. The difference in volumetric consumption is insignificant. Larger differences were observed in fuel mass consumption and energy use. Regarding that idling fuel consumption is most affected by engine auxiliaries, this difference cannot be considered significant. Additionally, the relatively large impact of pilot injection and short injection times increase the relative importance of premixed combustion on overall combustion during the engine cycle in idle mode.

Therefore, the changes in fuel consumption are more objectively characterized by the different driving modes. The experimental results were statistically evaluated by calculation of $95 \%$ confidence intervals that are also shown in Figs. 4 and 5. The fuel consumption results are shown in Fig. 4.

The difference in fuel consumption varies between driving modes. In the volumetric domain, NExBTL consumption is apparently higher by approximately $3 \%$, but the differences are statistically insignificant. Quite an opposite situation is observed in the mass flow domain. The fuel mass consumption of NExBTL is 5.3\% lower compared to diesel, but again in some test modes difference is statistically insignificant. To evaluate and compare the efficiency of different fuels, the analysis of energy supply and conversion can be the most meaningful. By looking at fuel consumption in the energy domain, the trend is like the one observed with fuel mass consumption. This time the average fuel energy that is supplied to the engine is $4.5 \%$ lower in the case of NExBTL. As driving in steady speed and driving cycles requires similar torque using both fuels, it can be assumed that energy conversion efficiency in conditions that are typical in tested vehicles engine is higher for paraffinic synthetic fuel NExBTL, compared to regular diesel fuel. These findings also explain why at assumed similar 
volumetric fuel consumption during maximal torque and power test runs the torque/power curves are so close to each other.
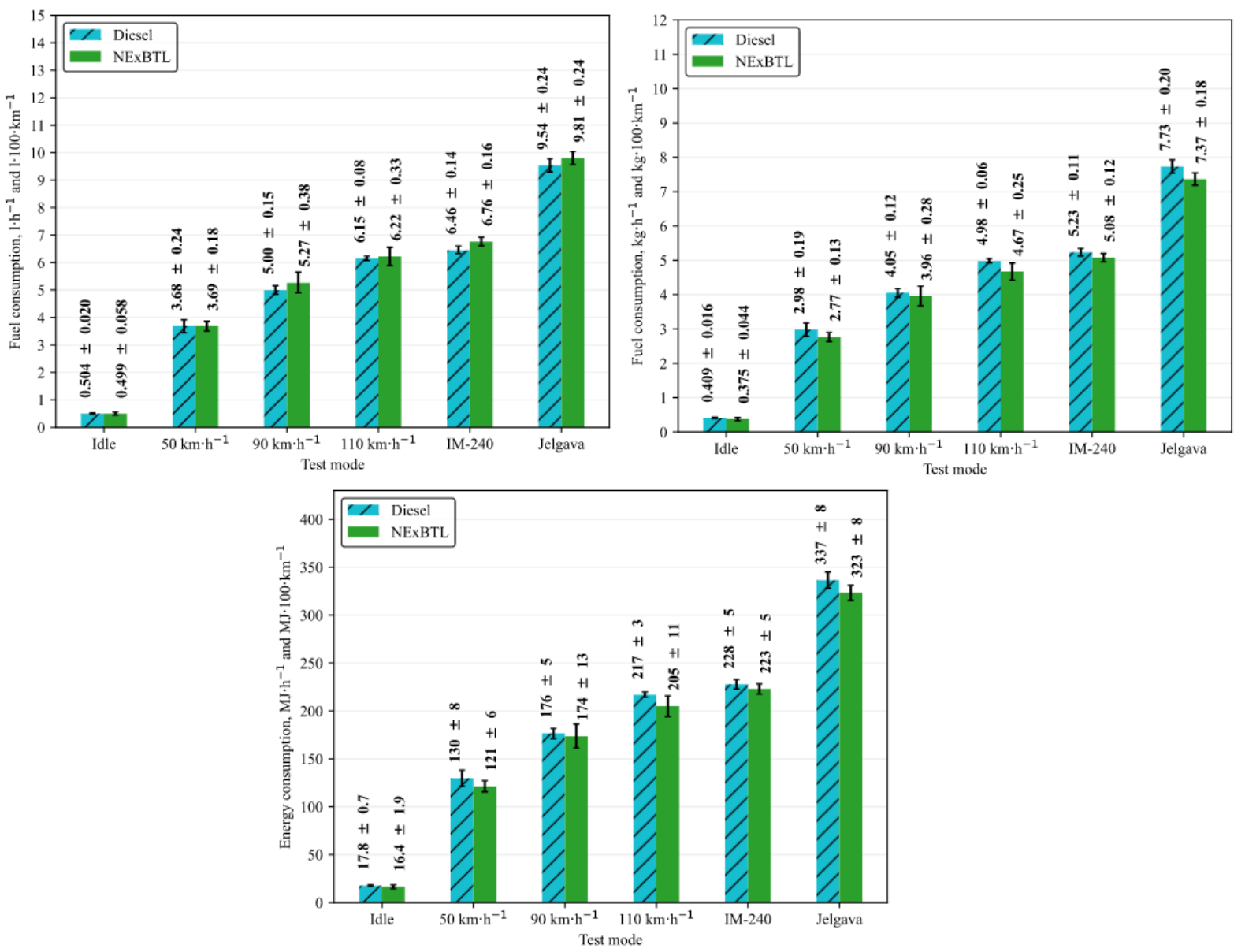

Fig. 4. Fuel consumption, shown in volumetric, mass and energy domains

The changes of $\mathrm{NO}_{\mathrm{x}}$, unburned hydrocarbons $(\mathrm{HC}), \mathrm{CO}_{2}$ and $\mathrm{SO}_{2}$ concentration in exhaust gases running the car with both fuels are shown in Fig. 5. The concentration of all exhaust gases is given in ppm (parts per million), except $\mathrm{CO}_{2}$, where it is shown in percent for better readability. Statistical evaluation is done using the same methodology as for fuel consumption and $95 \%$ confidence intervals are shown in bar plots. Only the results from constant engine speed test modes (idle, 50, 90 and $110 \mathrm{~km} \mathrm{~h}^{-1}$ ) are shown, as the interpretation of driving cycle data requires the calculation of massspecific emissions that are not included in this report.

Observed $\mathrm{CO}_{2}$ concentration in the case of NExBTL is lower by approximately $3.8 \%$. This result can be explained by the fact that the hydrogen to carbon ratio for NExBTL is 2.14, i.e., significantly higher, compared to the typical diesel fuel, 1.88 [12-13]. During complete combustion of NExBTL, relatively more $\mathrm{H}_{2} \mathrm{O}$ and less $\mathrm{CO}_{2}$ is produced, compared to diesel fuel.

The use of NExBTL instead of diesel fuel also led to a statistically insignificant reduction of $\mathrm{SO}_{2}$ emissions. Oil derived products, such as diesel fuel, contain sulphur, which is removed during the fuel production to the level specified by the corresponding standard. On the other hand, synthetic fuel, such as NExBTL, which is made from biological sources, normally has very few sulphur compounds. According to analytic data by Sugiyama et al., diesel fuel has $6 \mathrm{ppm}$ of sulphur, but NExBTL has only 3 ppm [12]. That explains the observed results of this research. Less sulphur in exhaust gases can prolong the useful service life of exhaust gas after-treatment devices. It can also reduce the emission of particle matter (PM) [14].

The effect of NExBTL on $\mathrm{NO}_{x}$ emissions was less pronounced, comparing to other gas species, analysed in this research. Only at the highest load conditions, steady driving at speed $110 \mathrm{~km} \cdot \mathrm{h}^{-1}$, a statistically insignificant reduction was observed, compared to the use of diesel fuel. As NExBTL has a 
higher cetane number than diesel fuel, the combustion will start earlier in the engine cycle. Normally it can lead to increased pressure and temperature that further might lead to the increased NO formation.
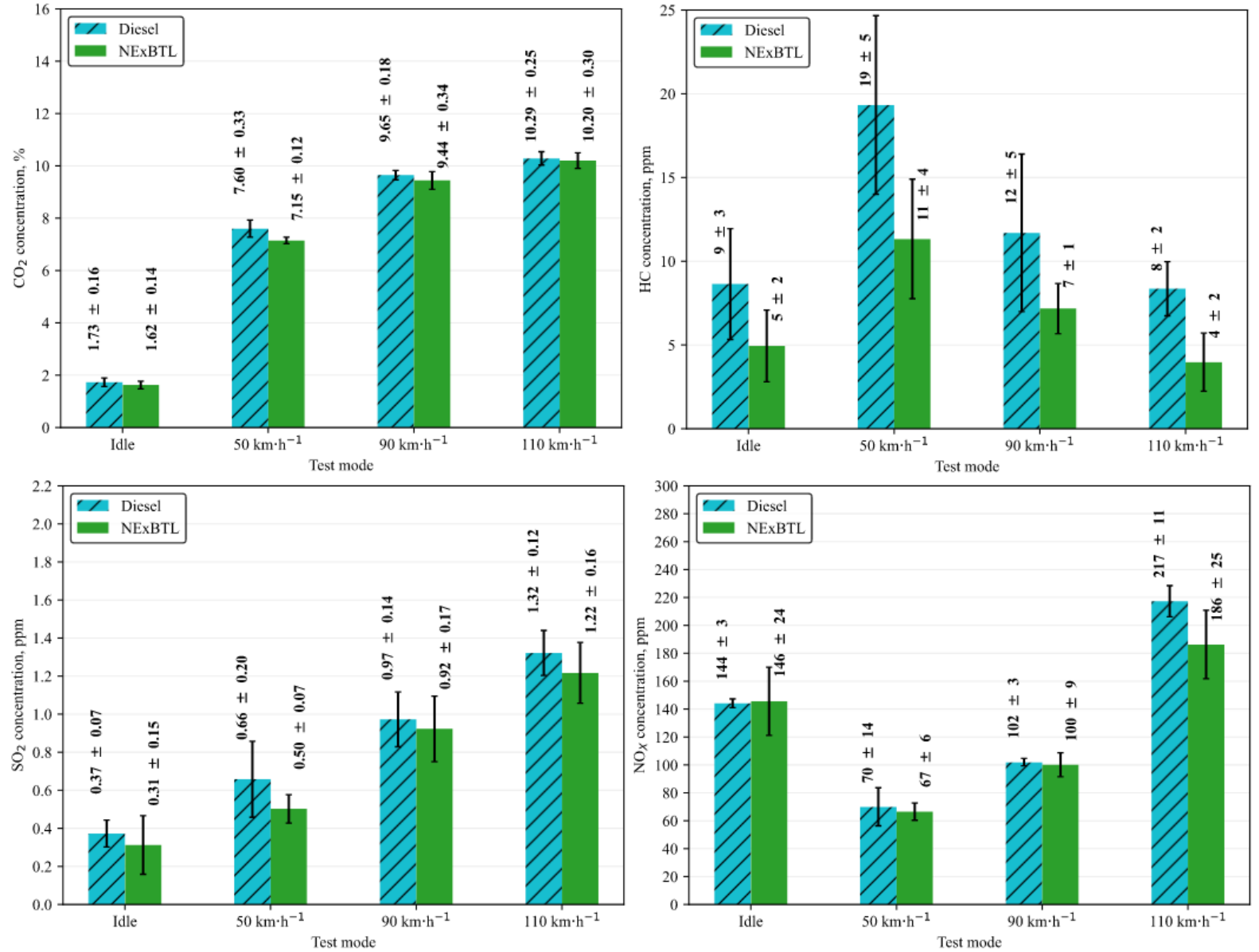

Fig. 5. Concentration of $\mathrm{CO}_{2}, \mathrm{HC}, \mathrm{SO}_{2}$ and $\mathrm{NO}_{\mathrm{x}}$ in vehicle-out exhaust gases

In low and middle engine speed pilot injection is typically used and it can be assumed so also for the engine in this study. The increase in fuel cetane number pronounces as a shorter ignition delay during combustion of the fuel injected during pilot injection and less so following the main injection. The described effect of pilot injection and comparison of apparent heat release rate curves between NExBTL and diesel fuel is shown in the work of Sugiyama et al. [12]. According to Heywood, the main source of NO production in a diesel engine is the diffusion combustion phase, which starts after pilot combustion and the premixed phase of following main injection is finished [15]. Additionally, higher compressibility of paraffinic fuel, compared to regular diesel fuel leads to delayed injection, which reduces pressure, temperature and $\mathrm{NO}$ formation [9]. The detailed results of $\mathrm{NO}_{\mathrm{x}}$ composition, calculated by equation (1) are not included for the brevity of this paper, but $\mathrm{NO}_{2}$ was approximately $55 \%$ and NO just $45 \%$ of the volumetric part of total nitrogen oxides for both tested fuels. Normally, $\mathrm{NO}_{2}$ should be between 10 to $30 \%$ of nitrogen oxides diesel engine-out emissions [15]. That means that in this research the composition of nitrogen oxides in exhaust gases are affected by gas after-treatment systems.

Significant reductions of approximately $44 \%$ of HC emissions when NExBTL was used were observed. According to Heywood, there are two main pathways for hydrocarbons to escape compete combustion in diesel engines - fuel mixture becomes too lean to ignite during premixed combustion that follows ignition delay, and the fuel-air mixture becomes too rich to ignite during the diffusion-controlled combustion phase [15]. As NExBTL has a significantly higher cetane number, that leads to shorter ignition delay and less pronounced premixed combustion phase. That might lead to a reduction of $\mathrm{HC}$ emissions that might originate during the premixed combustion phase. The result of $\mathrm{HC}$ concentration is calculated by AVL SESAM FTIR gas analyser software, using equation (2). This parameter needs deeper investigation in future research, as some species of hydrocarbons might be not accounted. 
Besides, it is important to note that gas samples were taken from the vehicle exhaust pipe, and the concentration of gas species is significantly altered by the catalytic converter and diesel particulate filter (DPF).

Comparing the obtained results with other studies, it is confirmed that was mentioned in the introduction, i.e., the tendencies of changes of various parameters differ depending on the used fuel properties and test objects. Similar to Singer et al. study [4], HC in the exhaust gas decrease, but no increase in $\mathrm{NO}_{\mathrm{x}}$ is observed. Compared with Bortel et al. study [5], very similar results were obtained for the reduction of $\mathrm{CO}_{2}$ and $\mathrm{NO}_{\mathrm{x}}$, but the reduction of $\mathrm{HC}$ is approximately twice as small. The increase in fuel consumption is very similar to that found by Rimkus et al. research [6]. However, there is a less significant reduction in $\mathrm{NO}_{x}$ and $\mathrm{CO}_{2}$ concentrations. $\mathrm{HC}$ change trends are close. The changes in $\mathrm{CO}_{2}$ are also very close compared to Suarez-Bertoa et al. study [7], but they did not identify significant changes in other exhaust components. The fact that no decrease in power and torque was observed with HVO is consistent with Sugiyama et al. investigation [12], which found that the injection quantity of $\mathrm{HVO}$ has to be $3 \%$ to $5 \%$ higher than diesel, but this results in no power loss with HVO in a common rail-equipped engine, even though the energy content on a volume basis is approximately less by $5 \%$.

\section{Conclusions}

1. The trial results prove that the car's power and torque characteristics using both fuels, i.e., NExBTL and diesel fuel, in the whole range of the engine speed are similar. The difference in maximum power is $0.34 \%$, but the maximum torque difference $-0.75 \%$. Concerning the accuracy of the equipment, the differences in power and torque are considered insignificant.

2. The average fuel volumetric consumption of NExBTL fuel is about 3\% higher than that of diesel. This can be explained by the differences in the physical properties of the two fuels. The calorific value of both fuels in MJ per kilogram is practically the same, but the density of fuels differs by more than $7 \%$. It causes a $6.5 \%$ difference in calorific value per litre of fuel.

3. Running on NExBTL, the vehicle used relatively less fuel mass by approximately $5.3 \%$ and less fuel energy by $4.5 \%$, compared to diesel fuel. Apparently more favourable mixture preparation and combustion occurred for NExBTL in tested engine and vehicle.

4. When analyzing the exhaust gases, the concentration of $\mathrm{CO}_{2}, \mathrm{SO}_{2}, \mathrm{NO}_{\mathrm{x}}$ and $\mathrm{HC}$ species tend to decrease compared to fossil diesel. A reduction was observed in most tested modes. The largest reduction of $\mathrm{NO}_{\mathrm{x}}$ concentration using NExBTL was observed at a higher engine load, at a steady speed of $110 \mathrm{~km} \mathrm{~h}^{-1}$. The average observed reduction is for unburned hydrocarbons - by $44 \%, \mathrm{SO}_{2}-$ by $13.3 \%, \mathrm{NO}_{\mathrm{x}}$ by $5 \%$ and $\mathrm{CO}_{2}-$ by $3.8 \%$.

5. Experimental studies on the Opel Insignia 2.0 CDTi with NExBTL allow suggesting that this fuel could compete with fossil diesel in the future. It is confirmed by measurements of power, fuel consumption and exhaust gas content. An essential factor in the broader introduction of this fuel is its price.

\section{References}

[1] European Parliament. Directive (EU) 2018/2001 of the European Parliament and of the Council on the promotion of the use of energy from renewable sources. Official Journal of the European Union, 2018 (L 328), pp. 82-209.

[2] No S.-Y. Application of hydrotreated vegetable oil from triglyceride based biomass to CI engines A review. Fuel, No. 115, 2014, pp. 88-96. DOI: 10.1016/j.fuel.2013.07.001

[3] Sonthalia A., Kumar N. Hydroprocessed vegetable oil as a fuel for transportation sector: A review. Journal of the Energy Institute, No. 92, 2019, pp. 1-17. DOI: 10.1016/j.joei.2017.10.008

[4] Singer A., Schröder O., Pabst C., Munack A., Bünger J., Ruck W., Krahl J. Aging studies of biodiesel and HVO and their testing as neat fuel and blends for exhaust emissions in heavy-duty engines and passenger cars. Fuel, No. 153, 2015, pp. 595-603. DOI: 10.1016/j.fuel.2015.03.050

[5] Bortel I., Vávra J., Takáts M. Effect of HVO fuel mixtures on emissions and performance of a passenger car size diesel engine. Renewable Energy, No. 140, 2019, pp. 680-691. DOI: 10.1016/j.renene.2019.03.067

[6] Rimkus A., Žaglinskis J., Stravinskas S., Rapalis P., Matijošius J., Bereczky Á. Research on the combustion, energy and emission parameters of various concentration blends of hydrotreated 
vegetable oil biofuel and diesel fuel in a compression-ignition engine. Energies, No. 12, 2019, 18 p. DOI: $10.3390 /$ en 12152978

[7] Suarez-Bertoa R., Kousoulidou M., Clairotte M., Giechaskiel B., Nuottimäki J., Sarjovaara T., Lonza L. Impact of HVO blends on modern diesel passenger cars emissions during real world operation. Fuel, No. 235, 2019, pp. 1427-1435. DOI: 10.1016/j.fuel.2018.08.031

[8] AVL SESAM-FTIR User's Manual, Gaggenau: AVL Emission Test Systems GmbH, 2007. 104 p.

[9] Sondors K., Birkavs A., Pirs V., Birzietis G., Dukulis I. Comparison of vehicle performance using fossil diesel fuel blends with biodiesel and HVO fuel. In: $18^{\text {th }}$ International scientific conference "Engineering for rural development": Proceedings, Volume 18, May 22-24, 2019. Jelgava: LLU, pp. 964-970. DOI: 10.22616/ERDev2019.18.N052

[10] Dukulis I., Pirs V. Development of driving cycles for dynamometer control software corresponding to peculiarities of Latvia. In: Proceedings of the $15^{\text {th }}$ International Scientific Conference "Research for Rural Development", May 20-22, 2009. Jelgava: LLU, pp. 95-102.

[11] Boehman A., Morris D., Szybist J., Esen E. The impact of the bulk modulus of diesel fuels on fuel injection timing. Energy \& Fuels, No. 6, Vol. 18, 2004, pp. 1877-1882. DOI: 10.1021/ef049880j

[12] Sugiyama K., Goto I., Kitano K., Mogi K., Honkanen M. Effects of hydrotreated vegetable oil (HVO) as renewable diesel fuel on combustion and exhaust emissions in diesel engine. SAE International Journal of Fuels and Lubricants, Volume 5, 2011, pp. 205-217.

[13] Labeckas G., Slavinskas S., Kanapkienè I. The individual effects of cetane number, oxygen content or fuel properties on the ignition delay, combustion characteristics, and cyclic variation of a turbocharged CRDI diesel engine - Part 1. Energy Conversion and Management, Vol. 148, 2017, pp. 1003-1027. DOI: 10.1016/j.enconman.2017.06.050

[14] Wang H., Hao H. Li X., Zhang K., Ouyang M. Performance of Euro III common rail heavy duty diesel engine fueled with Gas to Liquid. Applied Energy, No. 10, Vol. 86, 2009, pp. 2257-2261. DOI: 10.1016/j.apenergy.2009.02.004

[15] Heywood J.B. Internal Combustion Engine Fundamentals. New York: McGrawHill, 2018, 1028 p. 